\title{
Citogenotoxicidade de aromatizantes utilizados na fabricação de alimentos industrializados
}

\author{
Citogenotoxicity of food flavoring used in the manufacture of industrialized foods \\ Ila Monize Sousa Sales \\ Fabelina Karollyne Silva dos Santos \\ Ana Paula Peron \\ Universidade Federal do Piauí - UFPI - Teresina - Piauí - Brasil
}

\section{Resumo}

Objetivou-se no presente estudo avaliar a toxicidade em nível celular de aromatizantes de baunilha $(A B)$, nas doses $0,2,0,4,0,8$ e $1,6 \mathrm{~mL}$, e de Tutti-frutti (ATF), nas doses $0,3,0,6,1,2$ e 2,4 mL, combinados entre si, por meio de quatro associações, $A B$ 0,2 mL/ATF $0,3 \mathrm{~mL} ; A B \quad 0,4 \mathrm{~mL} / A T F ~ 0,6 \mathrm{~mL}$; $A B$ 0,8 mL/ATF 1,2 mL e AB 1,6 mL/ATF 2,4 mL. Para a análise da toxicidade utilizou-se as células meristemáticas de raízes de Allium cepa, que após a exposição as soluções aromatizantes, foram fixadas, hidrolisadas, coradas e analisadas em microscópio óptico. Os resultados obtidos foram avaliados pelo teste Qui-quadrado, a 5\%. Com base nos resultados obtidos verificou-se que todas as associações causaram efeito antiproliferativo as células do tecido analisado, bem como, número significativo de alterações de fuso mitótico. Dessa forma, as associações de baunilha e tutti-frutti, nas condições de análises estabelecidas para este estudo, foram citotóxicas e genotóxicas aos meristemas de raízes.

\section{Abstract}

The objective of the present study was to evaluate the toxicity at the cellular level of vanilla flavorings (VF), at doses of $0.2,0.4,0.8$ and $1.6 \mathrm{~mL}$, and of Tutti-frutti (ATF) at doses of 0.3; 0.6, 1.2 and $2.4 \mathrm{ml}$, combined with each other, in four combinations, VF $0.2 \mathrm{ml} / \mathrm{FTF} 0.3 \mathrm{ml}$, FF $0.4 \mathrm{~mL} / \mathrm{FTF}$ $0.6 \mathrm{~mL}$; VF $0.8 \mathrm{~mL} /$ FTF $1.2 \mathrm{~mL}$ and VF $1.6 \mathrm{~mL} /$ FTF $2.4 \mathrm{~mL}$. For the analysis of toxicity the meristematic cells of roots of Allium cepa were used, which after exposure to the flavors were fixed, hydrolyzed, stained and analyzed in optical microscope. The results were evaluated by the chi-square test, at 5\%. Based on the obtained results it was verified that all the associations caused antiproliferative effect to the cells of the analyzed tissue, as well as, significant number of mitotic spindle alterations. Thus, the associations of vanilla and tutti-frutti, under the conditions of analysis established for this study, were cytotoxic and genotoxic to root meristems.

\section{Palavras-chave}

Aditivos de aroma e sabor. Toxicidade. Ciclo celular. Alterações celulares.

\section{Keywords}

Aroma and flavor additives. Toxicity. Cell cycle. Cell changes. 


\section{Introdução}

Os aromatizantes são aditivos ou microingredientes alimentares capazes de conferirem ou reforçarem o aroma e o sabor dos alimentos industrializados sem o propósito de nutrir. São classificados como naturais, sintéticos idênticos aos naturais e sintéticos artificiais (KOCA et al., 2015). Possuem composição química complexa, constituídos de compostos como diluentes, antioxidantes, antiespumantes, conservantes, emulsificantes, estabilizantes, reguladores de acidez, realçadores de sabor, antiumectantes, antiaglutinantes, corantes, e solventes de extração e processamento (CHEESEMAN, 2015).

Mundialmente, os aditivos de aroma e sabor são normatizados e autorizados para uso pelos órgãos de segurança alimentar Food and Agriculture Organization (FAO) e Flavour and Extract Manufactuer Association (FEMA) (XU et al., 2015), e nacionalmente, pela Agência Nacional de Vigilância Sanitária (ANVISA) por meio da Resolução RDC no 2 de 15 de janeiro de 2007 (BRASIL, 2007). Entretanto, esses órgãos reguladores não informam em detalhes quais compostos e concentrações estão presentes nessas substâncias, assim como, não têm definidos o índice de Ingestão Diária Aceitável (IDA) e as doses limites toleráveis desses ingredientes para as diversas classes de alimentos industrializados disponibilizados comercialmente (BRASIL, 2007; MORE et al., 2012; ZEQUIN et al., 2011).

Assim, os aromatizantes são considerados um avanço polêmico da indústria de alimentos por alguns pesquisadores, como Pflanzer et al. (2010), Zaineddin et al. (2010), More et al. (2012), Honorato et al. (2013) e Carvalho et al. (2017), que alegam que esses microingredientes podem contribuir de forma significativa para o empobrecimento da dieta e no desencadeamento de patologias, principalmente em crianças. Além disso, pesquisadores como Pflanzer et al. (2010) e Zaineddin et al. (2010), alertam que a utilização de aromatizantes, com ênfases aos artificiais, suscita uma série de dúvidas quanto a sua toxicidade, principalmente em nível celular, uma vez que, trabalhos sobre o tema são escassos na literatura científica. Dessa forma, verifica-se a premência na realização de pesquisas que avaliem, por meio de sistemas testes adequados, os efeitos citotóxicos e genotóxicos desses aditivos alimentares.

O sistema teste Allium cepa oferece excelentes propriedades cinéticas de proliferação, cromossomos grandes e em número reduzido $(2 n=16)$ o que facilita a detecção de alterações de fuso mitótico e de quebras cromossômicas (LEME et al., 2008; HERRERO et al., 2011). Também permite a verificação de alterações no índice de divisão celular ou mitótico quando exposto a compostos químicos com potencial ação citotóxica (NEVES et al., 2014). Esse organismo de prova é aceito internacionalmente por agências de pesquisa como um instrumento de acurada sensibilidade para análise da citotoxicidade e genotoxicidade de substâncias de interesse, uma vez que, os resultados obtidos por intermédio dele demonstram, em grande parte das vezes, similaridade satisfatória a aqueles obtidos via sistemas testes animal e em culturas de células (GOMES et al., 2013; SANTANA et al., 2016). Como exemplo, pode-se citar os trabalhos realizados por Gomes et al. (2013) e Oliveira et al. (2013) que avaliaram em células meristemáticas de raízes de $A$. cepa o potencial tóxico de corantes sintéticos utilizados na indústria de alimentos e obtiveram resultados semelhantes aos obtidos em sistemas testes animais e com culturas de células.

Com base no contexto abordado, teve-se por objetivo avaliar a citotoxicidade e a genotoxidade de aromatizantes alimentares sintéticos artificiais de baunilha e tutti-frutti em 
combinação, uma vez que, esses dois aditivos são encontrados associados entre si em alimentos industrializados, como em pós para gelatinas, balas de goma, flans, cakes e refrigerantes.

\section{Material e métodos}

Os aditivos de aroma e sabor de baunilha e tutti-frutti foram obtidos de uma empresa localizada na cidade de Recife, Estado de Pernambuco - Brasil, especializada na fabricação e comercialização nacional e internacional de aditivos alimentares sintéticos em geral.

No rótulo do aromatizante de baunilha sugeria-se a utilização de $2 \mathrm{~mL}$ do aditivo para $1,0 \mathrm{Kg}$ de massa. Na embalagem do aditivo de Tutti-frutti recomendava-se $3 \mathrm{~mL}$ do aromatizante para $1,0 \mathrm{Kg}$ de massa. Os bulbos de $A$. cepa selecionados para a avaliação de toxicidade tinham, em média, $200 \mathrm{~g}$. Assim, as doses avaliadas no presente estudo dos dois aromatizantes foram estabelecidas de forma proporcional ao recomendado nos frascos dos microingredientes e ao peso dos bulbos utilizados nos experimentos. Portanto, a dose inicial de análise para o aromatizante de baunilha (AR) foi $0,4 \mathrm{~mL}$, e em seguida, estipulou-se três outras, 0,2, 0,8 e 1,6 mL. Já para o aromatizante de tutti-fruti (ATF) a dose inicial foi 0,6 mL, e logo após se determinou outras três, 0,3, 1,2 e 2,4 mL. Os aditivos de aroma e sabor em questão foram analisados associados entre si a partir das seguintes combinações de doses: $A B$ 0,2 mL/ATF 0,3 mL; AB 0,4mL/ATF 0,6 mL; AB 0,8 mL/ATF 1,2 mL e AB 1,6 mL/ATF 2,4 mL.

Para a realização do bioensaio com $A$. cepa, bulbos de cebola foram postos em frascos com água destilada, à temperatura ambiente $( \pm 27 \stackrel{-C}{)})$ que foram aerados constantemente, até a obtenção de raízes de $2,0 \mathrm{~cm}$ de comprimento. Para a análise de todo tratamento utilizou-se cinco bulbos de cebola. Antes de colocar os bulbos em contato com os seus respectivos tratamentos, algumas raízes foram coletadas e fixadas para servirem de controle do próprio bulbo. Em seguida, as raízes restantes foram postas em suas respectivas soluções por 24 horas, procedimento denominado de tempo de exposição 24 horas. Após este tempo foram retiradas algumas raízes e fixadas.

Feito tal procedimento, as raízes restantes de cada cebola foram devolvidas aos seus respectivos tratamentos onde permaneceram por mais 24 horas, o que se denominou de tempo de exposição 48 horas. Após esse período, raízes novamente foram coletadas e fixadas. A fixação das raízes se deu em Carnoy 3:1 (etanol: ácido acético) por 24 horas. Em cada coleta, retirou-se, em média, três raízes por bulbo. Portanto, todo tratamento foi constituído de três grupos de análise, o Controle, o Tempo de Exposição 24 horas e o Tempo de Exposição 48 horas, e para cada grupo analisou-se um total de 5.000 células, ou seja, mil células por bulbo. O procedimento descrito para a coleta de dados por meio do sistema teste $A$. cepa utilizou como parâmetro os trabalhos de Gomes et al. (2013), Oliveira et al. (2013), Sales et al. (2016), Campos-Ventura e Marin-Morales (2016) e Martins e Peron (2017).

O preparo das lâminas foi realizado com base no protocolo proposto por Guerra e Souza (2002). Em seguida as lâminas foram analisadas em microscópio óptico em objetiva de 40x, onde se observou células em interfase, prófase, metáfase, anáfase e telófase para a determinação do índice de divisão celular ou índice mitótico. Avaliou-se também a ação dos tratamentos com base na frequência de alterações de fuso mitótico, como as alterações ocasionadas pelo não alinhamento correto dos cromossomos na placa equatorial, as decorrentes do atraso de cromossomos durante a movimentação ocasionada pelas fibras do 
fuso mitótico, as oriundas de quebras cromossômicas com a formação de fragmentos acêntricos e/ou cromossomos em atraso que permaneceram à deriva na célula ao final da divisão celular, entre outros distúrbios celulares. Os resultados obtidos foram analisados pelo teste estatístico Qui-quadrado $\left(\chi^{2}\right)$, a 5\%, por meio do programa BioEstat 4.0.

\section{Resultados e discussões}

Conforme descrito na Tabela 1, as quatro combinações de doses de baunilha e tuttifrutti causaram redução expressiva da divisão celular nos tecidos meristemáticos de raízes logo no menor tempo de análise estabelecido. Para cada associação, observou-se que os índices de divisão celular dos tempos de exposição 24 e 48 horas foram significativamente menores que o índice mitótico observado para o seu respectivo controle. No entanto, em uma mesma associação os índices mitóticos dos dois tempos de exposição avaliados não foram significativos entre si. Por conseguinte, as associações avaliadas no presente estudo foram citotóxicas por terem causado efeito antiproliferativo relevante aos meristemas de raízes.

Tabela 1 - Número de células observadas em cada fase do ciclo celular presentes em tecido meristemático de raízes de Allium cepa tratados com água e com os aromatizantes alimentares sintéticos artificiais de baunilha, nas doses 0,2, 0,4, 0,8 e 1,6 $\mathrm{mL}$ e Tutti-frutti, nas doses de 0,3; 0,6, 1,2 e 2,4 mL, associados entre si, e avaliado nos tempos de exposição 24 e 48 horas.

\begin{tabular}{|c|c|c|c|c|c|c|c|c|}
\hline \multicolumn{9}{|c|}{ AROMATIZANTE DE BAUNILHA / AROMATIZANTE DE TUTTI-FRUTTI } \\
\hline $\begin{array}{l}\text { Doses associadas } \\
(\mathrm{ml})\end{array}$ & TE & TCll & $\mathrm{P}$ & M & A & $\mathrm{T}$ & TCD & IM (\%) \\
\hline \multirow{3}{*}{ AB $0,2 / A T F 0,3$} & $\mathrm{CO}$ & 4482 & 246 & 139 & 84 & 49 & 518 & $10,4^{\mathrm{a}}$ \\
\hline & $24 \mathrm{~h}$ & 4861 & 75 & 30 & 23 & 11 & 139 & $2,8^{b}$ \\
\hline & $48 \mathrm{~h}$ & 4883 & 50 & 28 & 26 & 13 & 117 & $2,3^{b}$ \\
\hline \multirow{3}{*}{ AB 0,4/ ATF 0,6 } & $\mathrm{CO}$ & 4085 & 599 & 161 & 93 & 62 & 915 & $18,3^{\mathrm{a}}$ \\
\hline & $24 \mathrm{~h}$ & 4597 & 173 & 128 & 55 & 47 & 403 & $8,1^{b}$ \\
\hline & $48 \mathrm{~h}$ & 4646 & 166 & 105 & 41 & 42 & 354 & $7,1^{\mathrm{b}}$ \\
\hline \multirow{3}{*}{ AB 0,8 / ATF 1,2 } & $\mathrm{CO}$ & 4016 & 628 & 152 & 97 & 102 & 979 & $19,7^{\mathrm{a}}$ \\
\hline & $24 \mathrm{~h}$ & 4621 & 185 & 110 & 41 & 43 & 379 & $7,6^{b}$ \\
\hline & $48 \mathrm{~h}$ & 4664 & 164 & 97 & 38 & 37 & 336 & $6,7^{b}$ \\
\hline \multirow{3}{*}{ AB 1,6 /ATF 2,4 } & $\mathrm{CO}$ & 4276 & 413 & 131 & 99 & 81 & 724 & $14,5^{\mathrm{a}}$ \\
\hline & $24 \mathrm{~h}$ & 4677 & 147 & 91 & 53 & 32 & 323 & $6,5^{b}$ \\
\hline & $48 \mathrm{~h}$ & 4741 & 113 & 97 & 31 & 18 & 259 & $5,2^{b}$ \\
\hline
\end{tabular}

AB: Aromatizante de Baunilha; ATF: Aromatizante de Tutti-Frutti; TE: Tempo de exposição; TCII: Total de Células em Interfase e Indiferenciadas; P: Profase; M: Metáfase; A: Anáfase; T: Telófase; TCD: Total de Células em Divisão; IM: Índice Mitótico. Para cada tratamento, valores de IM seguidos da mesma letra não diferem significativamente ao nível de $5 \%$ pelo teste $\chi^{2}$.

O potencial citotóxico de compostos ou substâncias químicas pode ser determinado pelo aumento ou diminuição do índice mitótico dos tecidos expostos a eles (FERNANDES et al., 2007). De acordo com Caritá e Marin-Morales (2008), índice mitóticos inferiores ao controle negativo indicam a presença de agentes cuja ação tóxica compromete o crescimento e o desenvolvimento dos organismos expostos a eles. Complementando a citação destes autores, Gomes et al. (2013) declaram que a inibição da proliferação celular desencadeada por 
compostos citotóxicos em tecidos de intensa proliferação celular e com desempenho normal ou sem alterações celulares, como os utilizados nesta pesquisa para avaliação dos aditivos de baunilha e tutti-frutti em associação, é bastante prejudicial ao organismo, uma vez que possui a propriedade de inibir ou limitar a reposição de células, alterar a produção de proteínas e, consequentemente, resultar no mal funcionamento do órgão onde está localizado.

Com base nos resultados da Tabela 2, verificou-se que as quatro associações de aromatizantes avaliadas causaram número expressivo de alterações de fuso mitótico as células do organismo de prova utilizado. As variações observadas foram metáfases poliploides, metáfases com perda de cromossomos, metáfases colchicínicas, pontes anafásicas, pontes telofásicas, micronúcleos e células binucleadas. Em razão desse resultado, as associações de baunilha e tutti-frutti, nas condições de estudo estabelecidas, demonstraram relevante atividade genotóxica.

Tabela 2 - Número e tipos de alterações celulares observadas em células de tecido meristemático de raízes de Allium cepa tratados com água e com os aromatizantes alimentares sintéticos artificiais de Baunilha, nas doses 0,2, 0,4, 0,8 e 1,6 mL e Tutti-frutti, nas doses de 0,3, $0,6,1,2$ e 2,4 mL, associados entre si, e avaliados nos tempos de exposição 24 e 48 horas.

\begin{tabular}{cccccccc}
\hline $\begin{array}{c}\text { Doses associadas } \\
(\mathrm{mL})\end{array}$ & TE & MP & MPC & PAT & MCN & CB & TAC \\
\hline \multirow{2}{*}{ AB 0,2/ATF 0,3 } & CO & 00 & 00 & 00 & 00 & 01 & 01 \\
& $24 \mathrm{~h}$ & 01 & 11 & 27 & 57 & 07 & $123^{\mathrm{b}}$ \\
& $48 \mathrm{~h}$ & 03 & 22 & 30 & 52 & 03 & $114^{\mathrm{b}}$ \\
\hline & $\mathrm{CO}$ & 01 & 00 & 00 & 00 & 00 & $01^{\mathrm{a}}$ \\
$\mathrm{AB} \mathrm{0,4/} \mathrm{ATF} \mathrm{0,6}$ & $24 \mathrm{~h}$ & 04 & 21 & 53 & 42 & 11 & 131 \\
& $48 \mathrm{~h}$ & 04 & 30 & 45 & 31 & 15 & $125^{\mathrm{b}}$ \\
\hline & $\mathrm{CO}$ & 00 & 00 & 00 & 01 & 00 & $01^{\mathrm{a}}$ \\
$\mathrm{AB} \mathrm{0,8} \mathrm{/} \mathrm{ATF} \mathrm{1,2}$ & $24 \mathrm{~h}$ & 01 & 39 & 34 & 51 & 19 & $144^{\mathrm{b}}$ \\
& $48 \mathrm{~h}$ & 01 & 31 & 43 & 67 & 17 & $159^{\mathrm{b}}$ \\
\hline & $\mathrm{CO}$ & 00 & 00 & 01 & 00 & 00 & $01^{\mathrm{a}}$ \\
$\mathrm{AB} \mathrm{1,6} \mathrm{/ATF} \mathrm{2,4}$ & $24 \mathrm{~h}$ & 05 & 27 & 39 & 75 & 27 & $173^{\mathrm{b}}$ \\
& $48 \mathrm{~h}$ & 01 & 27 & 52 & 74 & 33 & $187^{\mathrm{b}}$ \\
\hline
\end{tabular}

AB - Aromatizante de Baunilha; ATF - Aromatizante de Tutti-frutti; TE - Tempo de Exposição; MP: Metáfase Poliplóide; MPC - Metáfase com Perda de Cromossomo; PAT: Ponte Anafásica e Telofásica; MCN - Micronucleo; CB - Célula Binucleada; TCA: Total de Células com Alterações. Valores de IM seguidos da mesma letra dentro de um mesmo tratamento não diferem significativamente entre si ao nível de $5 \%$ pelo teste $\chi^{2}$.

Aissa et al. (2012) relatam que metáfases com alinhamento incorreto de cromossomos na placa equatorial, as denominadas metáfases- $C$ e as metáfases com perda de cromossomo, podem desencadear a formação de células binucleadas e também, após sucessivas divisões celulares, a formação de metáfases poliploides. Ainda, outras alterações celulares, tais como as pontes anáfasicas e telofásicas, poderão dar origem a células micronucleadas. Essas variações de fuso mitótico quando recorrentes ocasionam células com números cromossômicos distintos. Assim, considerando que o princípio do ciclo celular é a formação de células idênticas, a produção de células com alteração na estrutura e/ou no número 
cromossômico tornam o funcionamento celular inviável e tendem a ser eliminadas de tecidos com desempenho normal. Dessa forma, as variações significativas de fuso mitótico observadas nesse estudo corroboram aos resultados de redução da divisão celular descritos na Tabela 1.

Queiroz et al. (2013) ressaltam que micronúcleos quando em presença expressiva sinalizam que os compostos testados promoveram significativa toxicidade em nível celular, condição que pode causar relevante instabilidade genética nas células. É importante mencionar que, de acordo com esses autores, apesar da toxicidade genética não ser medida de carcinogenicidade, ela está frequentemente associada a processos cancerosos, visto que, há correlação positiva entre o aumento da frequência de micronúcleos e o aparecimento de tumores em mamíferos.

De acordo com Honorato et al. (2013) os aromatizantes em geral são considerados a classe de aditivos alimentares menos estudada do ponto de vista toxicológico. Porém, citam que a exposição prolongada a estes aditivos sintéticos desencadeiam hiperatividade em crianças, diminuição significativa na concentração de hemoglobina, alterações drásticas no funcionamento do fígado, perda de peso, alergias, hipersensibilidade cutânea e má digestão em adultos. No entanto, ressaltam que tais resultados, até o momento, são considerados inconclusivos por muitos pesquisadores. Ainda, a ANVISA, apesar de não citar em documento quais estudos, concentrações e aromatizantes (doce ou salgado) determinaram tal conclusão, declara que doses elevadas de aromatizantes alimentares provocam ações irritantes e narcóticas ao organismo, assim como, produz toxicidade crônica ao trato digestório se utilizados a longo prazo (BRASIL, 2007). Diferentemente, Salinas (2002) em seu trabalho menciona que a utilização de aromatizantes alimentares de modo geral, em baixas concentrações, não promove risco a saúde humana. Entretanto, quando as doses são elevadas, este autor relata que estes aditivos causam ações irritantes e narcóticas ao ser humano. Da mesma forma que a ANVISA, Salinas (2002) não especifica quais doses são consideradas altas ou baixas e quais aromatizantes desencadeiam tais reações.

Como se pode observar poucas são as informações, e muitas vezes contraditórias entre si, sobre a toxicidade dos aromatizantes, e esses resultados quase sempre são sobre a toxicidade sistêmica dos mesmos. Portanto, verifica-se que embora a utilização de aromatizantes em alimentos seja permitida pela ANVISA, torna-se necessário e urgente estudos para se determinar, com propriedade, o potencial tóxico, com ênfase a toxicidade em nível celular, de aromatizantes alimentares. Ademais, é relevante citar que o presente grupo de pesquisa no momento está realizando análises da toxicidade celular dos aromatizantes aqui discutidos de forma individual, tanto em sistemas testes vegetal como em animal. Cabe também ressaltar que o este estudo foi uma avaliação preliminar de avaliação do potencial tóxico dos aromatizantes, prezando a forma como são utilizados nas indústrias de alimentos.

\section{Conclusões}

As associações de baunilha e tutti-frutti avaliadas no presente estudo foram citotóxicas e genotóxicas ao bioensaio as células meristemáticas de raízes de $A$. cepa desde as menores doses avaliadas e o menor tempo de análise considerado. 


\section{Referências}

1. AISSA, A. F.; BIANCHI, M. L. P.; RIBEIRO, J. C.; HeRnANDES, L. C.; FARIA, A. F.; MERCADANTE, A.Z. Comparative study of $\beta$-carotene and microencapsulated $\beta$ carotene: Evaluation of their genotoxic and antigenotoxic effects. Food Chemical and Toxicology, 50, p. 1418-1424, 2012.

2. BRASIL. Agência Nacional de Vigilância Sanitária. Resolução-RDC n. 2, de $\mathbf{1 5}$ de janeiro de 2007. Aprova o Regulamento Técnico sobre as atribuições de aditivos em geral e seus limites máximos para a categoria e alimentos. Disponível em: http://portal.anvisa.gov.br/documents/33916/391619/Resolu\%25C3\%25A7\%25C3\%25A 30\%2BRDC\%2Bn\%25C2\%25BA\%2B3\%252C\%2Bde\%2B15\%2Bde\%2Bjaneiro\%2Bde\%2B20 07.pdf/8073d0d6-fe22-4af8-99d6-fe0788a91448.

3. CARITÁ, R.; MARIN-MORALES, M. A. Induction of chromosome aberrations in the Allium cepa test system caused by the exposure of seeds to industrial effluents contaminated with azo dyes. Chemosphere, 72, p. 722-725, 2008.

4. CARVAlho, B. L.; SALES, I. M. S.; PERON, A. P. Cytotoxic, genotoxic and mutagenic potential of UHT whole milk. Food Science and Technology (Campinas), 37, p. 275-279, 2017.

5. CHEESEMAN, M. A. Artificial food color additives and child behavior. Environmental Health Perspectives, 20, p. 15-16, 2012.

6. FERNANDES, T. C. C.; MAZZEO, D. E. C.; MARIN-MORALES, M. A. Mechanism of micronuclei formation in polyploidizated cells of $A$. cepa exposed to trifluralin herbicide. Pesticide Biochemmistry and Physiology, 88, p. 252-259, 2007.

7. GOMES, K. M. S.; OliVEIRA, M. V. G. A.; CARVALHO, F. R. S.; MENEZES, C. C.; PERON, A. P. Citotoxicity of food dyes sunset yellow (E-110), bordeax red (E-123), and tatrazine yellow (E-102) on Allium cepa L. root meristematic cells. Food Science and Technology, 33, p. 218-223, 2013.

8. GUERRA, M.; SOUZA, M. J. Como observar os cromossomos: um guia de técnicas em citogenética vegetal, animal e humana. Ribeirão Preto: FUNPEC, 2002. 340 p.

9. HeRRero, O.; MARTín, J. P.; FREIRE, P. F.; LÓPEZ, L. C.; PEROPADRE, A.; HAZEN, M. J. Toxicological evaluation of three contaminant of emerging concern by use of Allium cepa test. Mutation Reserch, 743, p. 24-34, 2012.

10. hONORATO, T. C.; BASTISTA, E.; NASCIMENTO, K. D. O. D.; PIRES, T. Aditivos alimentares: aplicações e toxicologia. Revista Verde, 81, p. 01-11, 2013. 
11. KOCA, N.; ERBAY, Z.; KAYMARK-ERTEKIN F. Effects of spray-driping conditions on the chemical, physical and sensory properties of cheese poder. Journal of Dairy Science, 98, p. 2934-2943, 2015.

12. LACERDA, L. P.; MALAQUIAS, G.; PERON, A. P. Antiproliferative action of aqueous extracts of Mart. (Fabaceae) on the cell cycle of Allium cepa L. Anais da Academia Brasileira de Ciências, 86, p. 1147-1150, 2014.

13. LEME, D. M.; ANGELIS, D. D. F.; MARIN-MORALES, M. A. Action mechanisms of petroleum hydrocarbons present in waters impacted by an oil spill on the genetic material of Allium cepa root cells. Aquatic Toxicology, 88, p. 214-219, 2008.

14. MARTINS, H. A.; PERON, A. P. Toxicidade de bebidas lácteas achocolatadas do tipo não fermentadas em tecido de intensa proliferação celular. Ciência e Natura, 39, p. 33-39, 2017.

15. MORE, S. S.; RAZA, A.; VINCE, R. The butter flavorant, diacetyl, forms a covalent adduct with 2-deoxyguanosine, uncoils DNA, and leads to cell death. Journal of Agricultural of Food Chemistry, 60, p. 3311-3317, 2012.

16. NEVES, E. S.; FERREIRA, P. M. P.; LIMA, L. H.; PERON, A. P. Action of aqueous extracts of Phyllanthus niruri L. (Euphorbiaceae) leaves on meristematic root cells of Allium cepa L. Anais da Academia Brasileira de Ciências, 86, p. 1131-1137, 2014.

17. OlIVEIRA, M. V. A.; ALVES, D. D. L.; LIMA, L. H. G. M.; CASTRO, J. M. C.; PERON, A. P. Cytotoxicity of erytrosine (E-127), brilliant blue (E-133) and red 40 (E-129) food dyes plant test system. Acta Scientiarum. Biological Science, 5, p. 557-562, 2013.

18. PFLANZER, S. B.; CRUZ, A. G. D.; HATANAKA, C. L.; MAMEDE, P. L.; CADENA, R.; FARIA, J. A. F.; SILVA, M.A.A.P.D. Perfil sensorial e aceitação de bebida láctea achocolatada. Food Science and Technology, 30, p. 391-398, 2010. Doi: 10.1590/S010120612010000200016 .

19. QUEIROZ, F. M. D.; MATIAS, K. W. D. O.; CUNHA, M. M. F. D.; SCHWARZ, A. Evaluation of (anti) genotoxic activities of Phyllanthus niruri L. in rat bone marrow using the micronucleus test. Brazilian Journal of Pharmaceutical Science, 49, p. 135-148, 2013.

20. SALES, I. M. S.; SANTOS, F. K. S.; SILVA, F. C. C.; SOUSA, J. M. C.; Peron, A. P. Microingredientes aromatizantes sintéticos artificiais em associação: triagem para a atividade citotóxica e genotóxica. Revista Brasileira de Biociências, 14, 233-237, 2016.

21. SALINAS, R.D. Alimentos e Nutricão: Introducão a Bromatologia. Porto Alegre: Artmed, 2002. $300 \mathrm{p}$. 
22. SANTANA, G. M.; DEUS, M. S. M.; SOUSA, J. M. C.; FERREIRA, P. M. P.; FERNANDES, H. B.; PERON, A. P. Antimitotic and antimutagenic action of the Hymenaea stigonocarpa bark on dividing cells. Brazilian Journal of Biology, 76, p. $520-525,2016$.

23. XU, Z.; GU, C.; WANG, K.; JU, J., WANG, H.; RUAN, K.; FENG, Y. Arctigenic acid, the key substance responsible for the hypoglycemic activity of Fructus Arctii. Phytomedicine, 22, p. 128-137, 2015.

24. ZAINEDDIN, A. K.; BUCK, K.; VRIELING, A.; GEINZ, J.; FLESCH-JANYS, D.; LINSEISEN, J. The association between dietary lignans, phytoestrogen-rich foods, and fiber intake and postmenopausal breast cancer risk: a German case-control study. Nutrition and Cancer, 64, p. 652-665, 2012.

25. ZEQUIN, N.; YÜZBAŞIOĞLU, D.; UNAL, F.; YILMAZ, S.; AKSOY H. The evaluation of the genotoxicity of two food preservatives: sodium benzoate and potassium benzoate. Food Chemical and Toxicology, 49, p. 763-69, 2011.

26. ZILIFDAR, F.; ALPER-HAYTA, S.; YILMAZ, S.; KAPLAN-ÖZEN, Ç.; FOTO, E.; AYDOĞAN, Z. Genotoxic potentials and eukaryotic DNA topoisomerase I inhibitory effects of some benzoxazine derivatives. Medicinal Chemistry Research, 23, p. 480-486, 2014. 